\title{
The influence of the amount and nature of dietary fat on milk fat composition in the sow
}

\author{
By R. C. WITTER AND J. A. F. ROOK \\ Division of Agricultural Chemistry, School of Agricultural Sciences, \\ University of Leeds
}

(Received 25 November 1969-Accepted 8 April 1970)

\begin{abstract}
I. The effects of the introduction into the diet of natural fats rich in individual fatty acids or of simple triglycerides on the composition of blood lipids and of milk fat in the sow were investigated.

2. Replacement in the diet of a mixture of animal, vegetable and marine oils by a single natural fat had varying effects on the concentrations of plasma lipid fractions, whereas replacement of tallow by simple triglycerides, with few exceptions, increased the concentrations of all fractions.

3. When butyric or caprylic acids were present in the diet there was no detectable transfer of those acids to plasma triglycerides, and there was only a limited transfer of dietary erucic acid. An increase in the dietary concentration of other acids (ranging from capric to linolenic) was associated with an increase in the content of the acids in the plasma triglycerides. For saturated fatty acids the response to dietary changes was at a maximum for myristic acid.

4. The effects on the composition of milk fat reflected the changes in the composition of the plasma triglycerides, except during the feeding of cottonseed oil when there were marked decreases in milk fat of palmitoleic and oleic acids and corresponding increases in palmitic and stearic acids which were not observed in the plasma triglycerides. Also, during the feeding of coconut oil, capric acid was present in the plasma triglycerides but not in milk fat, and the increases in the plasma triglycerides of lauric and myristic acids were much more marked than the corresponding increases in milk fat.
\end{abstract}

Salmon-Legagneur (1963, 1965) and Tollerz \& Lindberg (1965) have demonstrated that for certain fatty acids the output in milk fat is influenced by dietary intake. Relatively few acids, lauric, myristic, linoleic and linolenic, were studied and in total they account for less than $20 \%$ of the fatty acids of sow's milk. No evidence for the basis of the relationship was presented but it would be expected to involve the uptake of preformed fatty acids from the triglycerides of the plasma. An arteriovenous difference in the fatty acids of plasma triglycerides, and not of other lipid fractions, across the mammary gland of the lactating sow has been established (Linzell, Mepham, Annison \& West, 1969; Spincer, Rook \& Towers, 1969) and intravenous infusion of triglycerides rich in individual fatty acids has been shown to modify the composition of milk fat (Witter, Spincer, Rook \& Towers, 1970). The present work is concerned with a fuller investigation of the effect of the composition of dietary fat on the composition of milk fat in the sow and of the extent to which such effects are mediated through changes in the composition of plasma triglycerides.

\section{EXPERIMENTAL}

Animals and their management. Lactating animals were taken as required from the University herd of Wessex $\times$ Landrace $\times$ Large White sows. Sows with piglets were 
housed in open pens. Meal $(5 \cdot 5 \mathrm{~kg} /$ head per d) was offered to the sows twice daily, and they had free access to water. From the 3 rd week after farrowing, piglets had access to creep feed and water. During sampling periods, sows were confined to a holding crate and piglets to a separate pen. Suckling was permitted at intervals of $\mathrm{I} \cdot 5 \mathrm{~h}$.

Experimental details. A simple change-over design was adopted in which, over the 2nd-7th weeks of lactation, a 2-week experimental period was preceded and followed by 2-week control periods. Sows were introduced to the control diet during the Ist week of lactation.

Two experiments were done. In Expt $\mathrm{I}$ the diet offered during the control period was a basal, low-fat diet to which was added at a level of $2 \%(w / w)$ a blend of animal, vegetable and marine fats providing a wide spectrum of fatty acids. The effect of replacing the blended fat with coconut oil, red palm oil +tripalmitin $(\mathrm{I}: 3, \mathrm{w} / \mathrm{w})$, shea-nut oil, tristearin, cottonseed oil, linseed oil, rapeseed oil or tapioca starch was studied. When the blended fat was replaced by an isocaloric amount of tapioca starch, the daily amount of meal was increased to maintain the calorie intake. Each diet was given to two sows with the exception of those containing shea-nut oil and tristearin which were each offered to one sow only. In Expt 2, tallow was added to the basal, low-fat diet at a level of $2 \%(\mathrm{w} / \mathrm{w})$ and the tallow was replaced during experimental periods with a mixture of short-chain triglycerides:tributyrin + tricaprylin + tricaprin $(\mathrm{I}: \mathrm{I}: \mathrm{I}, \mathrm{W} / \mathrm{W})$, trimyristin + tallow $(\mathrm{I}: \mathrm{I}, \mathrm{W} / \mathrm{w})$, trimyristin, tripalmitin, triisostearin or triolein. The comparison involving triolein was made with two sows, other comparisons with a single sow.

Samples of coccygeal blood and of milk were taken on three occasions at $1 \cdot 5 \mathrm{~h}$ intervals during the morning of the last day of each 2-week period. Milk was removed manually from a number of teats after the injection of oxytocin (I i.u.) into an ear vein.

Preparation of experimental diets. The fat or oil (I part) was blended with tapioca starch (4 parts). This premix ( $3^{8}$ parts) was then machine-mixed with tapioca starch (240 parts), fish meal (33 parts), decorticated groundnut meal (27 parts), dried yeast ( 3 parts), limestone ( 3 parts), bone flour (4 parts), salt ( $\mathrm{r} 3$ parts), together with a complete vitamin and trace-mineral supplement. The composition of the basal, fatfree mixture was : dry matter, $89.7 \%$; protein (total $\mathrm{N} \times 6 \cdot 25$ ), i I.3\%; ether extract, $0.45 \%$; crude fibre, $0.66 \%$; ash, $5.33 \%$.

The oils were of commercial grade, containing roo ppm antioxidant (Topanol; Imperial Chemical Industries Ltd). The synthetic triglycerides were of 'Practical' grade (Fluka, A. G., Switzerland), except the tripalmitin used in Expt 2 and the triisostearin. The tripalmitin was specially prepared to contain $90 \%(\mathrm{w} / \mathrm{w})$ of the total fatty acids; palmitic acid and the triisostearin were synthesized from isostearic acid via the acid chloride.

Methods of analysis. The methods of analysis have been described previously (Witter et al. 1970). 


\section{RESULTS}

\section{Composition of the diets and their acceptance}

The fatty acid compositions of the diets are given in Table I. Diets were readily consumed. One sow which received triolein died suddenly during the final control period. Post-mortem analysis indicated that death was due to haemorrhage of the small intestine caused by a twist in the alimentary canal.

\section{Concentrations of plasma lipid fractions}

The results are given in Table 2 .

The substitution of cottonseed oil or of tristearin for blended fat caused increases in plasma triglyceride concentration, whereas the substitution of coconut oil, rapeseed oil or tapioca starch caused a decrease. With linseed oil opposite responses were observed in the two sows. Replacement of the blended fat was usually associated with a decrease in the concentrations of free cholesterol and of cholesterol esters. Exceptions were an increase in the concentration of cholesterol esters during the feeding of coconut and linseed oils and, in one sow, of tapioca starch, and of free cholesterol during the feeding of cottonseed oil. Phospholipid concentration increased following the substitution of rapeseed oil and tristearin and decreased on the substitution of red palm oil plus tripalmitin, linseed oil or tapioca starch.

Replacement of tallow with synthetic triglycerides resulted in all instances in an increase in the concentration of plasma triglycerides and, with few exceptions, also in the concentrations of other lipid fractions; the only consistent decrease was in the concentration of free cholesterol during the feeding of triolein.

\section{Fatty acid composition of the plasma triglycerides}

The results are reported in Table 3 and Fig. I. The two sows which received the 'fat-free' diet differed in their responses, and values are reported for each sow. With other diets offered to each of two sows, responses within the two sows were similar and a mean value is given.

Short-chain $\left(\mathrm{C}_{4}-\mathrm{C}_{10}\right)$ fatty acids were absent from the plasma of sows receiving the basal diet containing blended fat, and lauric acid was present only in trace amounts. Heptadecanoic, heptadecenoic, linolenic, eicosenoic and erucic acids were present in the plasma triglycerides either in trace amounts or only in low concentration and, with the exception of one pig, there was no detectable transfer from the diet of arachidic acid.

In Expt I, the presence of caprylic acid in the diet was not associated with the appearance of the acid in the plasma triglycerides, whereas dietary increases in capric, lauric and myristic acids raised their content in plasma triglycerides and this increase was greater with increasing chain length of the acid. The responses to the high dietary content of palmitic acid resulting from the substitution of red palm oil plus tripalmitin and to the high dietary content of stearic acid from the substitution of shea-nut oil were small, and introduction of tristearin decreased slightly the stearic acid content 


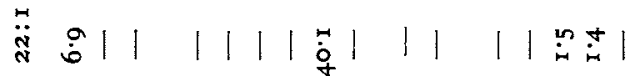

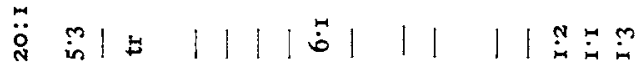

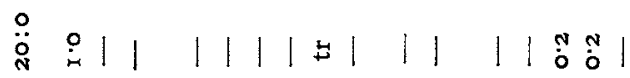

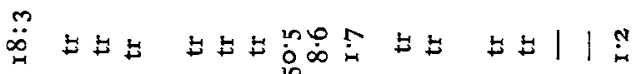

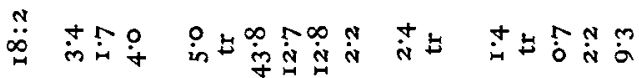

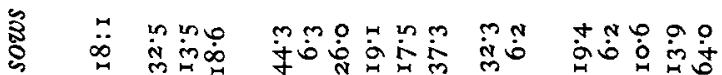

का

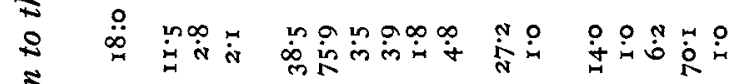

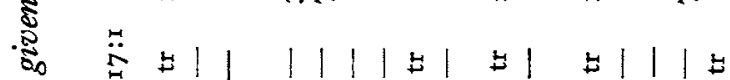

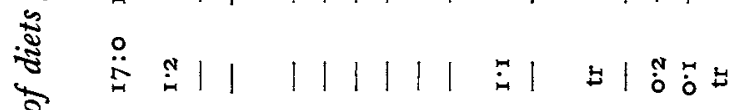

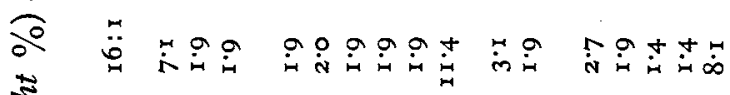

宽

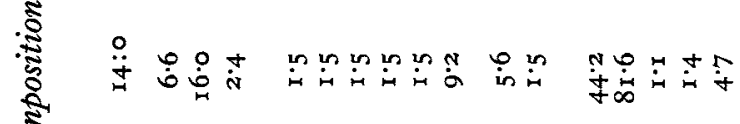

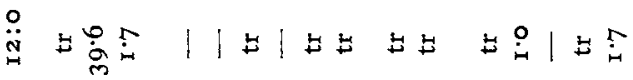

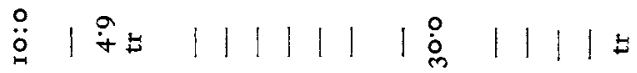

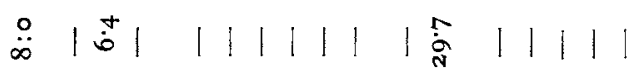

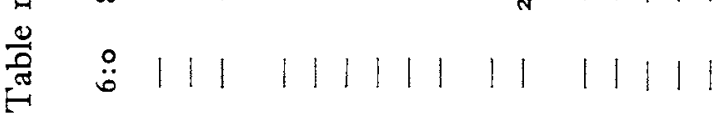

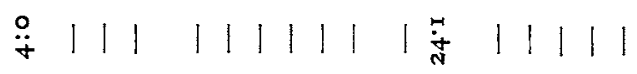

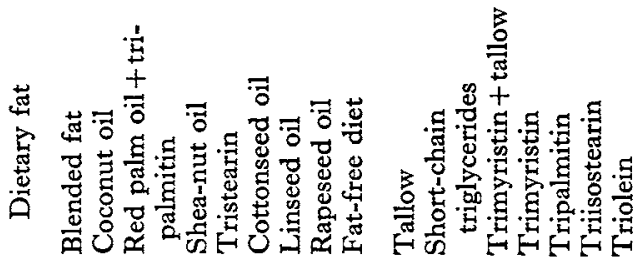

蓠富 
Vol. 24 Dietary fat and milk fat composition in the sow

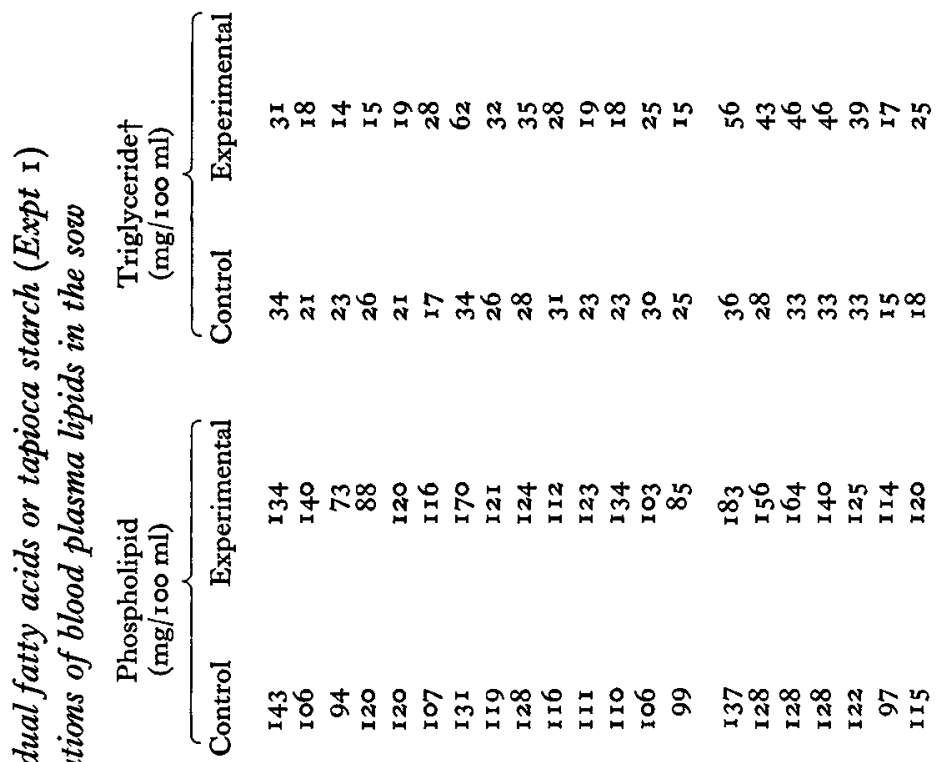

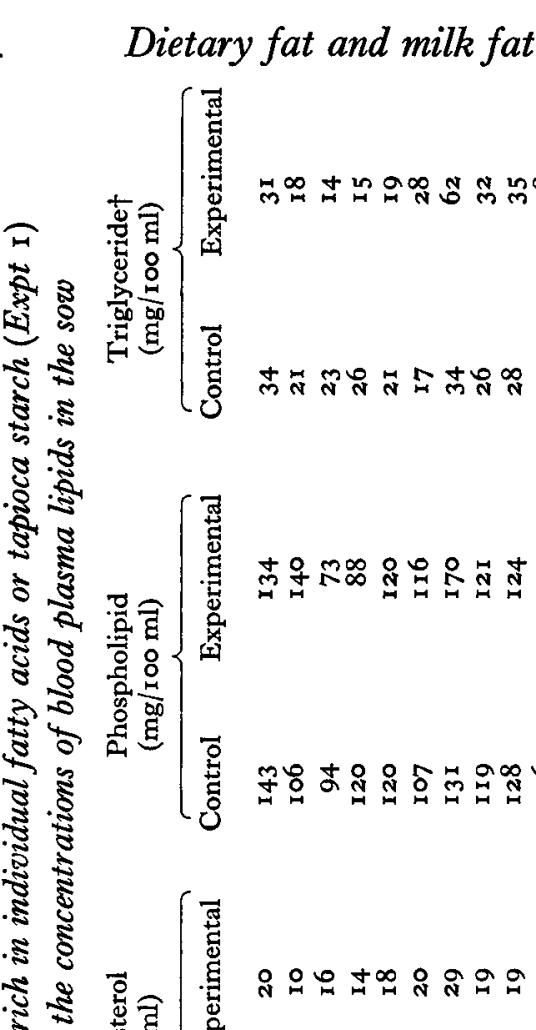

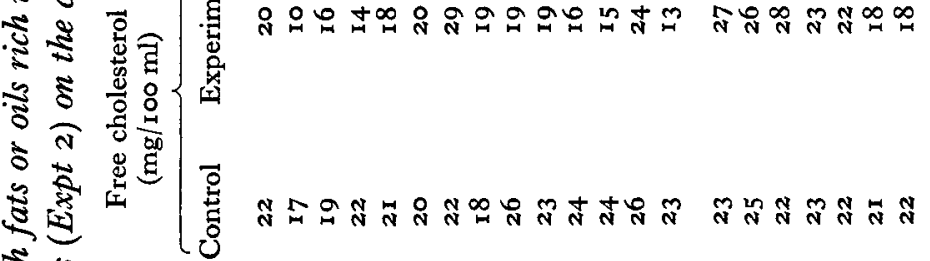

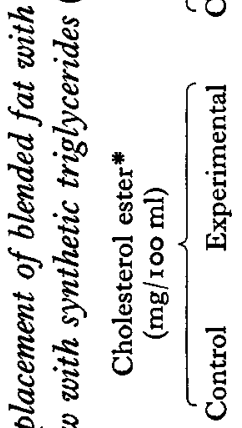

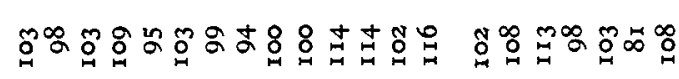

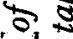

苂芯

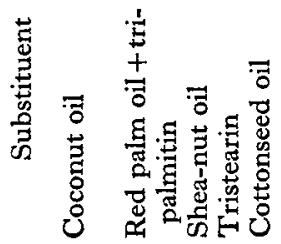

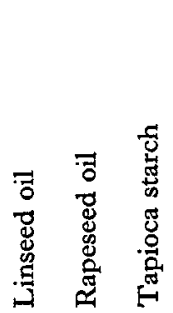

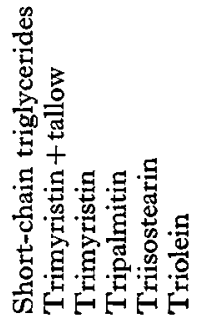

范官- 
$\stackrel{5}{3}$

$\stackrel{\substack{8 \\ 8}}{8}$

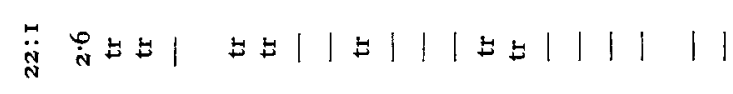

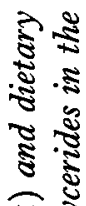

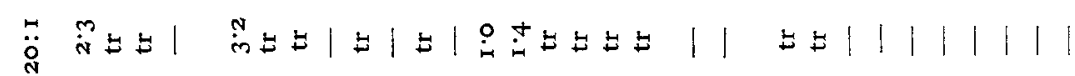

$\overparen{\pi}$

赵.

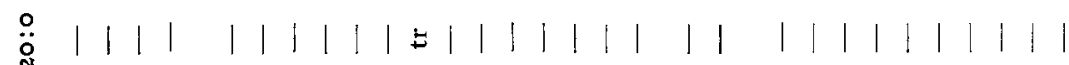

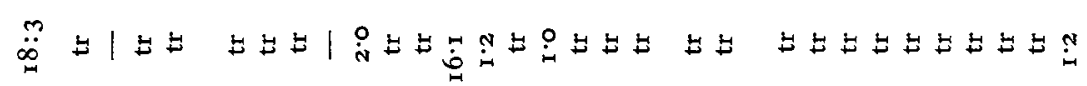
金

$\pi+40 \infty$ m 它

花

苟

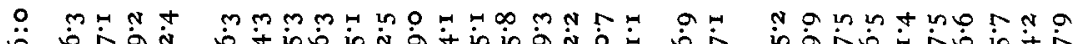
密

.

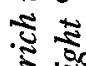

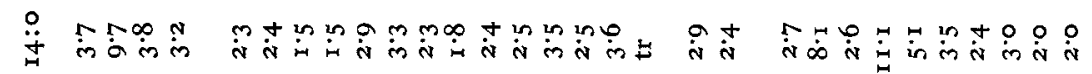

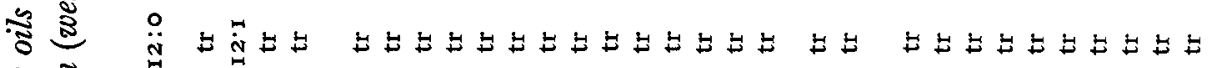
훙

芯茎
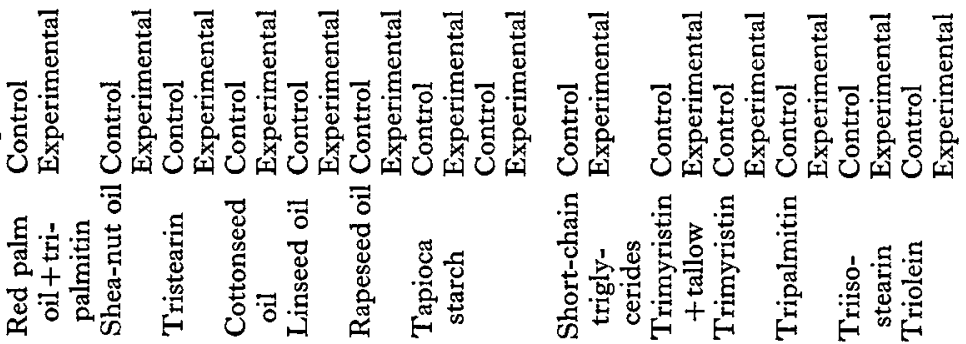

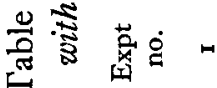


of plasma triglycerides. Increasing the dietary content of polyunsaturated $\mathrm{C}_{18}$ acids had a marked effect on their content in the plasma triglycerides but the high content of erucic acid in rapeseed oil was without effect on the plasma triglyceride content. Substitution of tapioca starch for the blended fat increased the oleic acid content of the plasma triglycerides, but in one sow there was a decrease in palmitic acid content and in the other an increase, and converse changes in linoleic acid content.

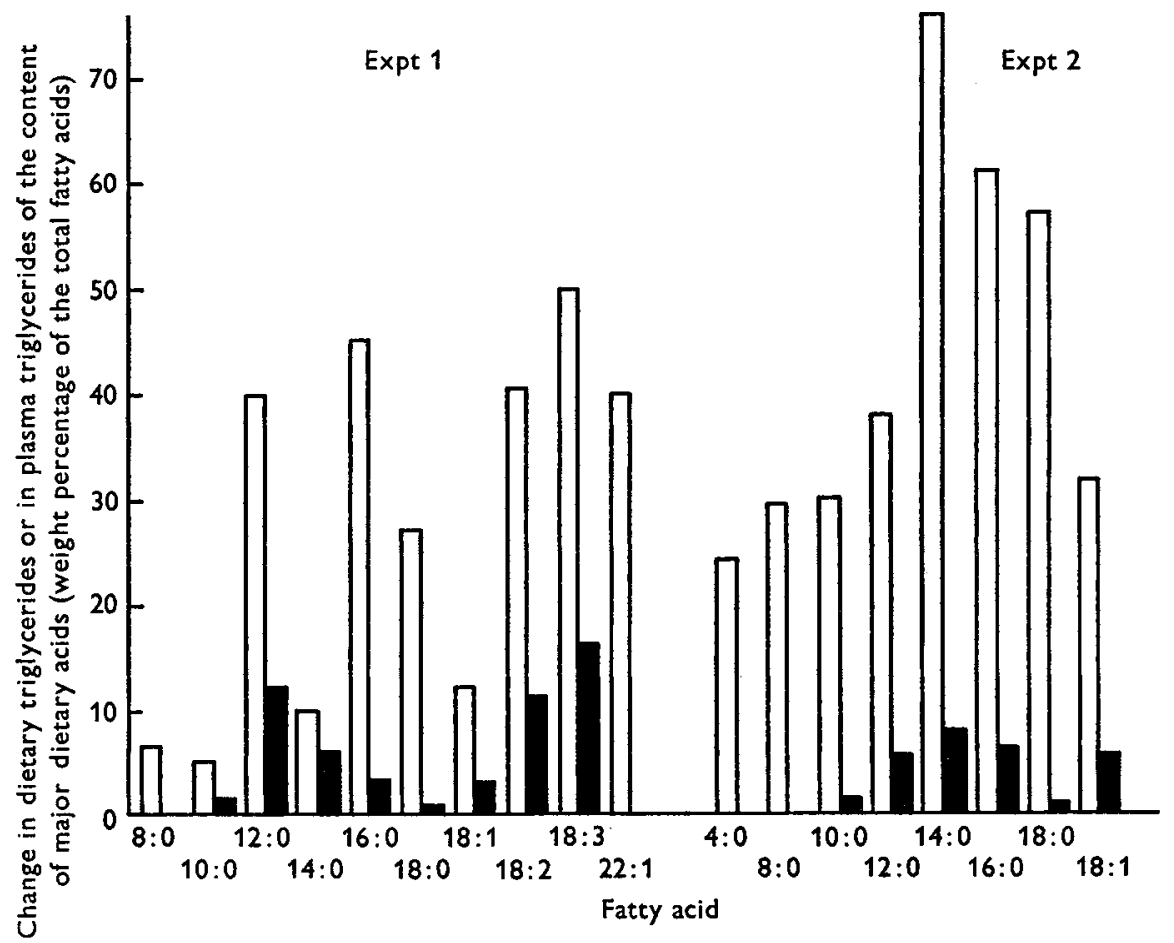

Fig. 1. Relationship in the sow between the changes in the content of major dietary acids in dietary triglycerides and in plasma triglycerides. The paired columns represent various diets which effected a major change in the intake of the fatty acid indicated on the abscissa (see Table I). $\square$, dietary triglycerides; $\square$, plasma triglycerides.

In Expt 2 there was no detectable transfer of butyric or caprylic acid to the plasma triglycerides during the feeding of the mixture of short-chain triglycerides, and only a slight transfer of capric acid. Substitution of trimyristin markedly increased the content of myristic acid in the plasma triglycerides but transfer appeared to be less efficient than for the myristic acid present in coconut oil (Expt I). However, substitution of 'tripalmitin', in which palmitic acid accounted for $90 \%(\mathrm{w} / \mathrm{w})$ of the fatty acids, produced a more marked increase in the palmitic acid content of the plasma triglycerides than did the mixture of red palm oil plus tripalmitin in Expt I, and there was additionally a slight increase in palmitoleic acid content. Substitution of triisostearin produced slight increases in the content of $\mathrm{C}_{18}$ saturated and monounsaturated acids in the plasma triglycerides. A more marked increase in the oleic acid content was observed in response to the introduction of triolein into the diet. 


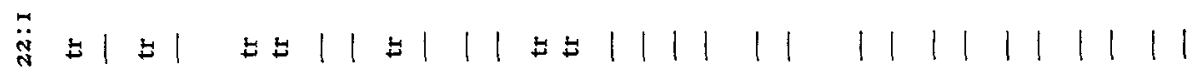

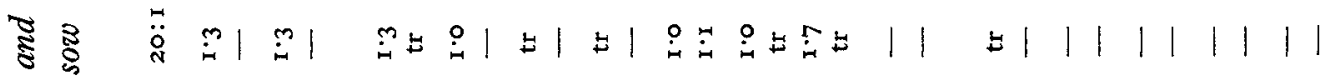

吾

tid.

is

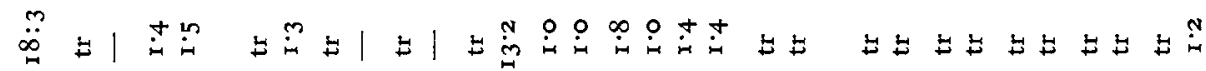

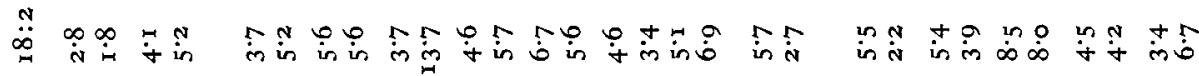

8

要

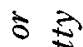

ت $\frac{2}{3}$

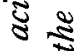

㝴官

क्ष

เู่

(⿻)

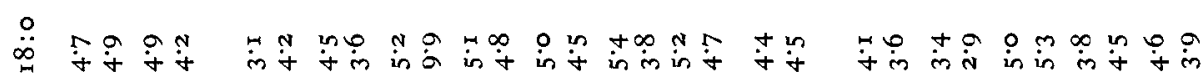

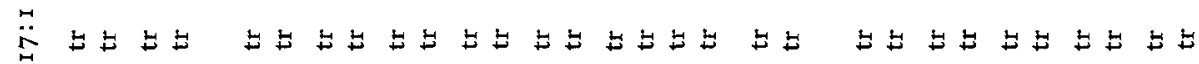
盆

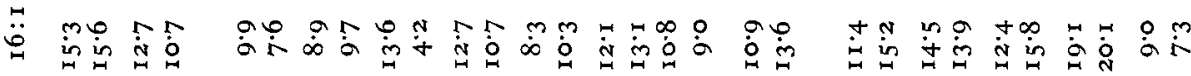

․ㅗ

$\sqrt{2}$

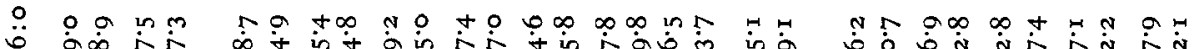

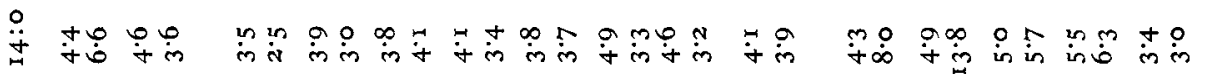

t)

$\overbrace{}^{2}$

ลิล

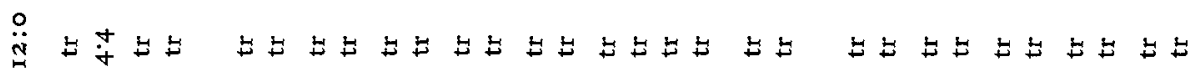

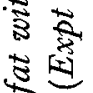

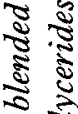

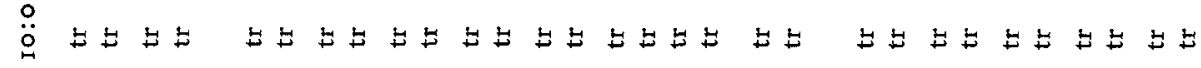

$\stackrel{\circ}{\infty}||||$

के.

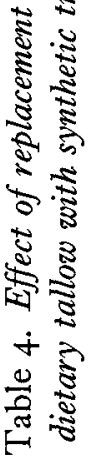

$\stackrel{\circ}{+}||||$
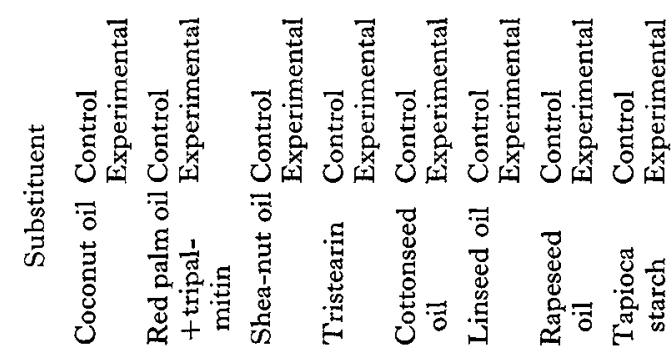

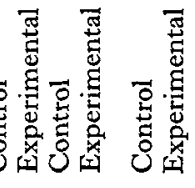

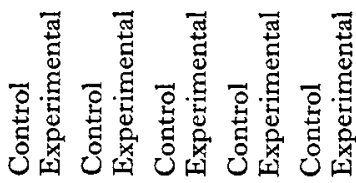

営宫-

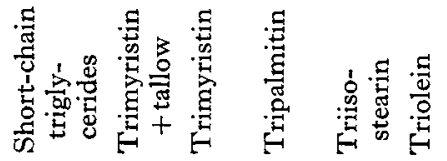


Increases in the content in the plasma triglycerides of saturated acids up to and including palmitic acid occurred mainly at the expense of $\mathrm{C}_{18}$ acids, and increases of oleic acid at the expense of palmitic acid, but when the $\mathrm{C}_{18}$ polyunsaturated acids increased there were compensatory changes in palmitic, stearic and oleic acids.

\section{Fatty acid composition of other plasma lipid fractions}

The composition of the free fatty acids of the plasma showed changes for the major dietary acid similar to those reported for the plasma triglycerides except that the changes in the contents of palmitic and oleic acids were more pronounced and in the

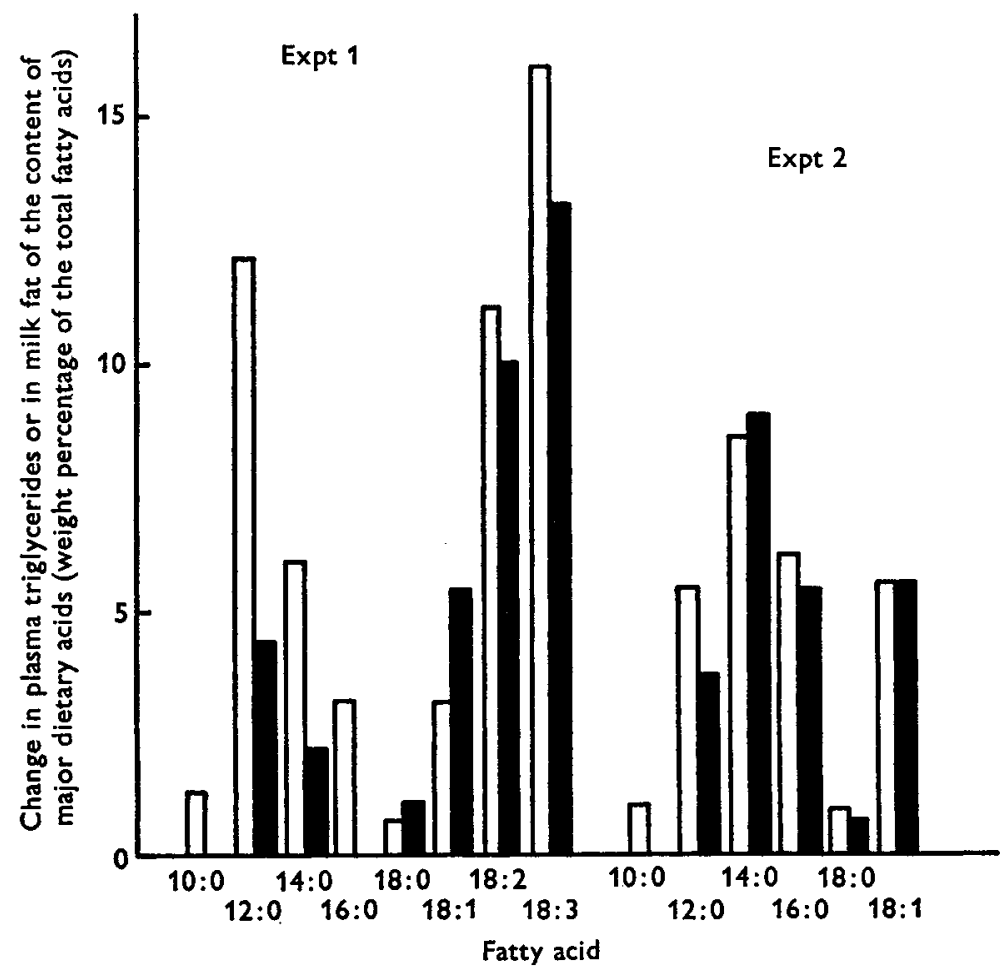

Fig. 2. Relationship in the sow between the changes in the content of major dietary acids in plasma triglycerides and in milk fat. The paired columns represent various diets which effected a major change in the intake of the fatty acid indicated on the abscissa (see Table $I$ ). $\square$, plasma triglycerides; $\mathbf{0}$, milk fat.

contents of other acids less pronounced. However, the substitution of tapioca starch for blended fats in Expt I produced changes in the plasma free fatty acids distinctly different from those observed in the plasma triglycerides. There was in both sows a decrease in the linoleic acid content, but a decrease in oleic acid and an increase in palmitic acid in one sow and opposite effects in the other sow. Dietary increases in myristic, linoleic and linolenic acids also caused increases in the corresponding acids in the cholesterol ester and phospholipid fractions; small increases in the lauric and oleic acid contents of the phospholipids were observed in response to increases in the diet of those acids. 


\section{Fatty acid composition of milk fat}

The results are given in Table 4 (details are as for Table 3 ). The introduction into the diet of oils and fats rich in individual fatty acids caused changes in the fatty acid composition of milk fat which reflected largely the changes in the composition of the plasma triglycerides (Fig. 2). There were two major exceptions. During the feeding of coconut oil, capric acid was present in the plasma triglycerides but not in milk fat, and the increases in plasma triglycerides in lauric and myristic acids were much more pronounced than the corresponding increase in milk fat. Also, the introduction of cottonseed oil was associated with marked decreases in milk fat of palmitoleic and oleic acids and corresponding increases in palmitic and stearic acids which were not observed in the plasma triglycerides. Introduction of tripalmitin, which was accompanied by a slight increase in the palmitoleic acid content of plasma triglycerides, caused a distinct increase in the palmitoleic acid content of milk triglycerides.

\section{DISCUSSION}

There are two established mechanisms for the absorption and transport of dietary fatty acids (Senior, 1964). The longer-chain fatty acids are mainly incorporated into triglycerides, and transported by the lymph in the form of chylomicra. The shorterchain fatty acids are, however, absorbed into the portal blood and transported as free fatty acid-albumin complexes to the liver where they are rapidly oxidized; the importance of this route increases with decreasing chain length of the fatty acid.

The observed effects on plasma triglyceride composition of dietary increases in butyric, caprylic, capric and lauric acids and of myristic acid present in coconut oil are consistent with this effect of chain length on absorption and metabolism. Also, the failure to detect butyric or caprylic acids in the plasma free fatty acids during the feeding of the mixture of short-chain triglycerides is consistent with a rapid catabolism of these acids. The responses in the plasma triglycerides to dietary changes in linoleic and linolenic acids were of the same order as that observed in myristic acid during the feeding of coconut oil but the responses in myristic acid, brought about by the introduction of trimyristin into the diet, and in palmitic, stearic, oleic and erucic acids were much less. The levels in the plasma triglycerides of the major acids, palmitic, stearic and oleic acids, may not be especially sensitive to changes in the uptake from the gut but for the longer-chain saturated acids, especially when present in the form of simple triglycerides, uptake may have been limited owing to a low digestibility. The apparent digestibilities of triglycerides rich in $\mathrm{C}_{16}$ and $\mathrm{C}_{18}$ saturated acids were determined in a separate experiment with the following results: tripalmitin, $61 \%$; tripalmitin containing $90 \%(\mathrm{w} / \mathrm{w}$ of the total fatty acids) palmitic acid, $77 \%$; tristearin, 13\%; triisostearin, $19 \%$. There is other evidence (Deuel, Hallman \& Leonard, 1940; Thomasson, 1956) that erucic acid is poorly absorbed. However, the efficiency of transfer of erucic and eicosenoic acids to plasma triglycerides appeared to vary between sows.

The different responses in plasma triglyceride fatty acids in the two animals in 
whose diets the dietary tallow was replaced by tapioca starch may have reflected differences in the fatty acid composition of the depot fats of the two animals. This composition is influenced by the nature of the fatty acids in the diet during pregnancy (Salmon-Legagneur, 1963, 1965), and mobilization of fatty acids from the depots takes place at times of low dietary fat intake. The changes in the plasma triglyceride fatty acids were not, however, accompanied by similar changes in the plasma free fatty acids, through which the changes would be expected to be mediated.

The observed effects of dietary fat composition on milk fat composition can be explained largely in terms of the associated changes in the fatty acid make-up of the plasma triglycerides and the responses to such changes observed in experiments in which artificial emulsions were infused intravenously (Witter $e t a l$. 1970); of the major added acids, the main exception was lauric acid during the feeding of coconut oil when an increase of lauric acid in the plasma triglycerides of $12 \%$ was associated with an increase of that acid in milk fat of $4 \%$, a proportionately much smaller response than that observed following the intravenous infusion of trilaurin (Witter et al. 1970). A similar, limited response in milk fat to changes in plasma triglyceride composition was apparent for myristic and capric acids during the feeding of coconut oil. As in the experiments in which artificial emulsions were infused intravenously (Witter $e t$ al. 1970), an increase in the plasma triglycerides of palmitic acid was associated with an increased output in milk triglycerides not only of palmitic acid but also of palmitoleic acid, owing to the presence in sow mammary tissue of a desaturase system (Bickerstaffe \& Annison, r968).

During the feeding of cottonseed oil, increases in the milk fat content of palmitic and stearic aciàs and decreases in palmitoleic and oleic acids were observed which were not accompanied by similar changes in the plasma triglycerides. There are several reports in the literature that the feeding of cottonseed oil to various species causes a hardening of their tissue lipids: in pigs (Ellis \& Isbell, 1926; Ellis, Rothwell \& Pool, 1931), in hens (Evans, Bandemer, Anderson \& Davidson, 1962) and in fish (Reiser, Stevenson, Kayama, Choudhury \& Hood, 1963). Tollerz \& Lindberg (1965) also noted a substantial decrease in the proportion of palmitoleic acid in sow's milk fat in response to cottonseed oil feeding. Evans $e$ al. (1962) suggested that the increased proportion of saturated acids was due either to an increased rate of hydrogenation of linoleate to stearate or to an interference with the desaturation mechanism by which palmitate and stearate are converted into their respective monoeneric acids. The sterculic and malvalic acids present in cottonseed oil were thought to be involved. Kircher (1964) and Reiser \& Raju (1964) were able to confirm that these cycloprenoid fatty acids interfere with desaturation mechanisms; the cycloprenoid group combines with the thiol group of the desaturase enzyme, limiting its activity and the conversion of saturated acids into their corresponding mono-enes.

We thank Mr T. G. Boaz and Mr A. F. Calder for the supply of animals and the provision of facilities at Leeds University farm, and Mr J. Spincer, Mr J. B. Hillcoat, Mr J. B. Hopwood and Mrs M. Davies for their help. The work was supported financially by a grant from The Pig Industry Development Authority, to whom we 
express our thanks. We are grateful to Price's Chemicals Limited, of Wirral, Cheshire, for gifts of tripalmitin and isostearic acid.

\section{REFEREN CES}

Bickerstaffe, R. \& Annison, E. F. (1968). Biochem. F. 108, 47 P.

Deuel, H. J., Hallman, L. Jr \& Leonard, A. (I 940). F. Nutr. 20,2 I 5.

Ellis, N. R. \& Isbell, H. S. (1926). F. biol. Chem. 69, 239.

Ellis, N. R., Rothwell, C. S. \& Pool, W. O. (1931). F. biol. Chem. 92, 385.

Evans, R. J., Bandemer, S. L., Anderson, M. \& Davidson, J. A. (1962). F. Nutr. 76, 314.

Kircher, H. W. (1964). F. Am. Oil Chem. Soc. 41, 4.

Linzell, J. L., Mepham, T. B., Annison, E. F. \& West, C. E. (r969). Br. F. Nutr. 23, 3r9.

Reiser, R. \& Raju, P. K. (1964). Biochem. biophys. Res. Commun. 17, 8.

Reiser, R., Stevenson, B., Kayama, M., Choudhury, R. B. R. \& Hood, D. W. (1963). F. Am. Oil Chem. Soc. 40, 507 .

Salmon-Legagneur, E. (1963). C. r. hebd. Séanc. Acad. Sci., Paris 257, 4221 .

Salmon-Legagneur, E. (1965). Annls Zootech. 14, no. Hors-série r.

Senior, J. R. (1964). F. Lipid Res. 5, 495.

Spincer, J., Rook, J. A. F. \& Towers, K. G. (1969). Biochem. Y. III, 727.

Thomasson, H. J. (1956). F. Nutr. 59, 343 .

Tollerz, G. \& Lindberg, P. (1965). Acta vet. scand. 6, I 18.

Witter, R. C., Spincer, J., Rook, J. A. F. \& Towers, K. G. (1970). Br. F. Nutr. 24, 269. 